\title{
Investigation of the Physical Properties of Jute Blended Yarn Using a Novel Approach in Spinning Process
}

\author{
Md. Abdus Shahid', A. K. M. Mahabubuzzaman², Farid Ahmed³, Ayub Ali4 \\ ${ }^{1}$ Department of Textile Engineering, Dhaka University of Engineering and Technology (DUET), \\ Gazipur, Bangladesh \\ ${ }^{2}$ Department of Mechanical Processing Division, Bangladesh Jute Research Institute (BJRI), Dhaka, Bangladesh \\ ${ }^{3}$ Department of Physics, Jahangirnagar University, Dhaka, Bangladesh \\ ${ }^{4}$ Department of Apparel Manufacture \& Technology, BGMEA University of Fashion and Technology (BUFT), \\ Dhaka, Bangladesh \\ Email: te_shahid@yahoo.com,drmahabub@gmail.com,fahmed_ju@yahoo.com,mayubtex11@yahoo.com
}

Received 9 December 2015; accepted 1 January 2016; published 3 February 2016

Copyright (C) 2016 by authors and Scientific Research Publishing Inc.

This work is licensed under the Creative Commons Attribution International License (CC BY).

http://creativecommons.org/licenses/by/4.0/

(c) (†) Open Access

\begin{abstract}
This work reports the successful outcomes to process the polyester, acrylic and wool fiber along with jute fiber exclusively using existing jute processing machineries for manufacturing the 241 tex jute blended yarn. The blending was performed at feeding stage of breaker carding machine and blending ratio of jute and polyester/acrylic/wool fibers is 80:20. Manufacturing of jute blended yarns will create a new opportunity for extending the uses of jute fibers in value added jute products. The present work is concerned with the investigation of physical properties such as tenacity, elongation \% at break, quality ratio, unevenness, imperfections (thick, thin $\&$ neps) and hairiness of manufactured jute blended yarns. The jute-polyester $(80 / 20)$ blended yarn shows the higher strength and more evenness compared to jute-acrylic $(80 / 20)$, jute-wool $(80 / 20)$ blended and $100 \%$ jute yarn.
\end{abstract}

\section{Keywords}

Jute, Blending, Tenacity, Quality Ratio, Unevenness, Imperfections

\section{Introduction}

Jute is a natural fiber popularly known as the golden fiber. It is one of the cheapest and the strongest of all natural fibers and is considered as fiber of the future [1]. Traditionally jute fiber has been used to manufacture the 
packaging materials like hessian, sacking, ropes, twines and home textiles as carpet, carpet backing cloth etc. [2]. In order to overcome the declining market of these conventional products of jute, new technologies and diversification have been evolved for bulk use of jute, as a raw material in the production of high value added and price competitive intermediaries or final products. Previous work reveals that some innovative new products have been developed with high value-addition such as home textiles, jute composites, jute geo-textiles, paper pulp, technical textiles, chemical products, handicrafts and fashion accessories etc. These products for new, alternative and non-traditional use of jute are generally termed as diversified jute products. Diversified use of jute fiber can redeem the lost glory of it. Recently, due to the improvement of people's living standards and need for environmental protection, the demand of natural biodegradable and eco-friendly fibers is rising worldwide day by day [3] [4]. The increased demand of natural fiber is due to their low cost, low density, biodegradability, renewability and abundance [5] [6]. So, the researchers are trying to diversify the uses of jute fiber.

The process of converting fibers into yarn is complex and requires many investigations and technical and technological solution [7]. Though, in case of jute blended yarn on existing jute spinning system is not understood thoroughly, a few reports [8] [9] are available on tensile properties. Nawaz, S.H. et al. [8] investigated the spinning performance for rotating ratios of jute/cotton, jute/viscose and jute/polyester blends to improve the tensile behavior of composites structures, fabricated at ring, rotor and air-jet spinning system. Sett S.K et al. [9] studied the influence of jute/viscose blending ratio on rotor and friction spun yarn properties and revealed that an increase in percentage of jute in blended yarns recorded a decrease, both in its tensile strength as well as elongation, while it helped to obtain an improved initial modulus.

The present work discovers a new concept \& technique for blending the jute with other fibers like polyester, acrylic, wool etc. to manufacture the novelty yarn using existing jute processing machineries. The objective of this experiment is to produce the jute blended yarns that will be used as value added product for home textiles, decorative fabrics, handicrafts, geotextiles, carpet backing cloth, shopping bags etc. Effective blending provides a better scope for utilizing the advantage of the intrinsic properties of the component fibers and performs mainly to endow the required characteristics to the end products, compensates for variation in the characteristics of the raw materials and to hold down raw material cost [10]. The physical and other properties of the manufactured blended yarn are investigated in order to know the quality. Physical properties of yarn are very important for post-spinning operations as well as for determining some final fabric characteristics. This study will be helpful as a guide line for jute enterprises to manufacture the jute blended yarn.

\section{Experimental}

Bangla white B (BWB) jute fibers were selected for blending with polyester/acrylic/wool fibers to carry out the present experiment. Physical properties of the jute, polyester, acrylic and wool fibers are provided in Table 1. Fiber fineness was measured by fiber fineness meter and tenacity \& breaking extension (\%) were evaluated by Pressley fiber bundle strength tester. 100\% BWB jute fibers were processing as usual practice for manufacturing the $100 \%$ jute yarn. The processing stages of usual practice are softening \& lubricating by softener machine, conditioning, carding by breaker \& finisher card, drawing by 1st, 2nd, \& 3rd draw frame and finally spinning by slip draft machine. On the other hand for manufacturing the blended yarn, the conditioned jute fibers were blended with other fiber manually at the feed lattice of the breaker carding machine. It is to be mentioned here that acrylic/polyester/wool fibers were opened by Hopper feeder machine before mixing with jute fibers during feeding in the feed lattice of breaker carding machine. The delivered slivers of breaker card were processing by finisher carding machine. The finisher card slivers were followed by three drawing process for better fiber

Table 1. Physical properties of selected fibers.

\begin{tabular}{ccccc}
\hline Parameters & Jute & Polyester & Acrylic & Wool \\
\hline Fiber length (mm) & - & 32 & 32 & 70 \\
Fineness (dtex) & 20 & 1.5 & 1.5 & 3.8 \\
Tenacity (gram per denier) & 4.2 & 3.5 & 3.0 & 1.41 \\
Breaking extension (\%) & 1.65 & 20 & 15 & 38 \\
\hline
\end{tabular}


straightening and parallelization. After finisher drawing, the slivers were fed to the flyer spinning machine to produce the required yarn count. The machineries were run at normal adjustment. Four types of yarn e.g. 100\% jute, jute-polyester, jute-acrylic, jute-wool were manufactured at normal adjustment of parameters.

\subsection{Processing Stages}

Softening \& lubricating: The softener machine consists of 64 pairs of rollers and these are spirally fluted and jute goes through them. When the jute passes one third of the rollers then the emulsion is added with spray. The jute fiber is on to the delivery sheet through delivery roller. It was manufactured by James Mackie \& Sons Lt. Ireland and its pair rollers were manufactured by Gidding \& Lewis Ltd., Scotland.

Conditioning: After softening and lubricating the jute fibers, it was conditioned (piling) for 24 hours.

Carding: The object of carding is to break down the strikes of jute and convert them into a continuous sliver of suitable weight per unit length [11]. In breaker card machine, soft jute fibers after piling was feed by hand and selected other (polyester/acrylic/wool) fibers was spreading over the jute fibers for blending in the feed lattice at suitable weight. The machine by action with different rollers turns out raw jute blended materials in the form of sliver for finisher carding. It was manufactured by James Mackie \& Sons Lt., Ireland. Jute-polyester breaker card sliver is shown in Figure 1. Finisher carding machine made the sliver more uniform and regular in length and weight from the breaker carding machine. Finisher card machine is identical to the breaker card, having more pair of rollers, staves, pinning arrangement and speed. 10 slivers obtained from breaker card machine were fed on the finisher card machine. Delivery sliver weight of finisher card was $17.50 \mathrm{lbs} / 100$ yards.

Drawing: Drawing is the process for reducing sliver weight per length by simultaneously mixing of sliver together. It makes the sliver light and more uniform by parallelization of the cress-cross fibers [12] [13]. The three drawing process was used. The slivers obtained from the finisher carding machine were fed with two slivers on to the first drawing machine. Two doublings were used for processing the jute blended materials. This machine includes delivery roller, pressing roller, retaining roller, faller screw sliders, check spring, back spring, crimpling box etc. The second drawing machine obtains the sliver from first drawing machine and uses doubling 3:1. It makes more uniform sliver and reduce the weight per unit length into suitable size for third drawing. Third drawing machine uses the slivers of second drawing machine and 2:1 doubling were maintained in this machine. The manufacture company of the drawing machines is James Mackie \& Sons Lt., Ireland.

Spinning: Spinning is the process for producing yarn from sliver obtained from third drawing sliver. In spinning process slivers are elongated and fibers are twisted into yarn to impart strength [14]. In this experiment, slip draft flyer spinning machine manufactured by James Mackie \& Sons Lt., Ireland was used for making yarn. This machine is widely used in Bangladesh jute mills.

\subsection{Tensile Properties}

The maximum force applied on a yarn to break it is called tensile strength [15]. Single yarn strength tester was used for measuring the tensile strength and breaking elongation. The tensile properties of yarn are accepted as

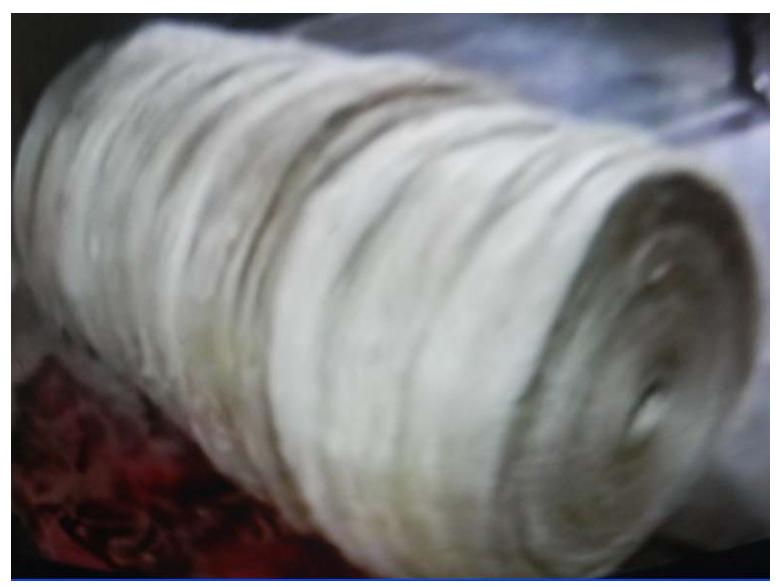

Figure 1. Jute-polyester blended card sliver. 
one of the most important parameters for assessment of yarn quality. The tensile properties decide the performance of post spinning operations; warping, weaving and knitting and the properties of the final textile structure; hence its accurate technical evaluation carries much importance in industrial applications [16] [17]. Tenacity, tensile strength, elongation, and quality ratio are important measuring parameters of tensile properties of yarn. The tenacity value is the ratio of tensile strength (gm) of single yarn and linear density (tex). Tenacity value of yarn was calculated by using the following formula:

$$
\text { Tenacity }(\mathrm{gm} / \mathrm{tex})=\frac{\text { Tensile strength }(\mathrm{gm})}{\text { Linear density }(\mathrm{tex})}
$$

Quality ratio (QR\%) is the ratio between tensile strength and linear density of the yarn expressed as percentage [18] [19]. QR\% was calculated by using the following formula:

$$
\text { Quality ratio }(\%)=\frac{\text { Tensile strength }(\mathrm{lbs})}{\text { Linear density }(\mathrm{lbs} / \text { spyndle })} \times 100
$$

\subsection{Evenness Properties}

Uster Tester 5 (UT-5) was used to investigate the evenness, imperfection (IPI) and surface integrity properties of jute blended yarn. This machine applies the capacitive method [20]. Speed of the machine was $50 \mathrm{~m} / \mathrm{minute}$ during testing. One minute was needed to complete the one test. The observed parameters were $\mathrm{Um} \%, \mathrm{CVm} \%$, thin $(-50 \%)$, thick $(+50 \%)$, neps $(+200 \%)$, neps $(+280 \%) \&$ hairiness of the jute blended yarn. Imperfections means the sum of thin $(-50 \%)$, thick $(+50 \%)$ and neps $(+200 \%)$ [21] [22]. The sensor for measuring the evenness of yarn was a capacitive measuring sensor. A high-frequency electric field was generated in the sensor slot between a pair of capacitor plates. If the mass between the capacitor plates changes, the electrical signal is altered and out signal of the sensor changes accordingly [23]. The result was an electrical signal variation proportional to the mass variation of the test material passing through. The analog signal was then converted into a digital, stored and processed directly by the UT- 5 computer.

In case of measuring the tensile and evenness properties of the yarn, the average of 10 readings was taken for each experiment.

\section{Results and Discussion}

Polyester, acrylic and wool fibers were selected for blending with jute fibers separately. Selected fibers were blended at the feeding stage of breaker carding machine. Jute blended yarns were manufactured using optimum processing parameters of the usual jute processing equipments. Jute fibers were blended with selected fibers at 80:20 ratios. Tensile properties of manufactured 241 tex jute blended yarns are given in Table 2 and evenness properties in Table 3. The results reveal that jute blended yarn shows higher tenacity, higher quality ratio comparing to $100 \%$ jute yarn while $\mathrm{CV} \%$ of tensile strength also are reducing.

Tenacity of jute-polyester blended yarn is increased by $24.59 \%$ compare to $100 \%$ jute yarn. The causes of this reason will be explained as number of fiber in yarn cross-section. When number of fibers will increase in same diameter of yarn, strength will be increased. Polyester, acrylic, wool are more fine fiber compare to jute fiber.

Appearance and surface integrity of yarn are related to fabric properties. Appearance integrity (consistency) is the most used characterization of spun yarns. All spinners aim at producing yarns of high appearance; that is low

\begin{tabular}{cccccc}
\multicolumn{7}{l}{ Table 2. Tensile properties of 241 tex jute blended yarn. } \\
\hline Mixing type & $\begin{array}{c}\text { Tensile strength } \\
\text { (lbs) }\end{array}$ & $\begin{array}{c}\text { Tensile strength } \\
\text { (CV\%) }\end{array}$ & $\begin{array}{c}\text { Elongation at } \\
\text { break (\%) }\end{array}$ & $\begin{array}{c}\text { Tenacity } \\
\text { (gm/tex) }\end{array}$ & $\begin{array}{c}\text { Quality } \\
\text { ratio (\%) }\end{array}$ \\
\hline Jute-Polyester & 8.40 & 7.26 & 3.40 & 15.81 & 120.00 \\
Jute-Acrylic & 7.90 & 7.26 & 3.50 & 14.87 & 112.86 \\
Jute-Wool & 7.45 & 7.09 & 2.32 & 14.02 & 106.43 \\
100\% Jute & 6.74 & 9.10 & 1.97 & 12.69 & 96.29 \\
\hline
\end{tabular}


Table 3. Evenness properties of 241 tex jute blended yarns.

\begin{tabular}{ccccccc}
\hline Mixing type & Um\% & CVm\% & $\begin{array}{c}\text { Thin/km } \\
(-50 \%)\end{array}$ & $\begin{array}{c}\text { Thick/km } \\
(+70 \%)\end{array}$ & $\begin{array}{c}\text { Neps/km } \\
(+280 \%)\end{array}$ & $\begin{array}{c}\text { Hairiness } \\
(-)\end{array}$ \\
\hline Jute-Polyester & 22.94 & 29.76 & 1445 & 562 & 143 & 9.88 \\
Jute-Acrylic & 23.17 & 29.87 & 1530 & 590 & 150 & 11.25 \\
Jute-Wool & 24.43 & 32.08 & 1427 & 823 & 185 & 11.22 \\
100\% Jute & 28.14 & 37.60 & 2660 & 1240 & 240 & 13.63 \\
\hline
\end{tabular}

unevenness value, minimum thick $\&$ thin places and minimum neps. The surface integrity includes hairiness, surface structure, diameter and shape (roundness) of the yarn. So, evenness properties are also measured and presented in Table 2. Appearance and surface properties of 241 tex jute blended yarn are more better compare to $100 \%$ jute yarn. Um\% (unevenness) value is the highest in $100 \%$ jute yarn i.e. $100 \%$ jute yarn is very uneven compare to others. Thin, thick and neps places in the yarn are comparatively less in jute-polyester (J/P), compare to jute-acrylic (J/A), jute-wool (J/W) blended yarn. Jute-polyester blended yarn showed the better appearance and surface properties compare to other blended yarns.

\section{Conclusion}

The results in this experiment demonstrated the successful outcome to attempt for manufacturing the 241 tex jute-polyester, jute-acrylic and jute-wool blended yarn using conventional jute processing equipments at mixing ratio 80:20. Jute blended yarns showed the better quality in terms of physical and evenness properties comparing with 100\% jute yarn. Among the mentioned three jute blended yarns, jute-polyester blended yarn showed higher tenacity and better evenness properties. The results showed that the tenacity and quality ratio of jute-polyester blended yarn was $15.81 \mathrm{gm} / \mathrm{tex}$ and $120.0 \%$ while jute-acrylic blended yarn showed $14.87 \mathrm{gm} / \mathrm{tex} \& 12.86 \%$, jute-wool blended yarn showed $14.01 \& 106.37 \%, 100 \%$ jute yarn showed 12.69 gm/tex \& 96.29\% respectively. The unevenness values for jute-polyester, jute-acrylic, jute-wool and $100 \%$ jute yarn were $22.94 \%$, $23.17 \%$, $24.43 \%$ and $28.14 \%$ respectively. The lowest imperfection value (thick, thin \& neps) was observed at jutepolyester blended yarn.

\section{Acknowledgements}

The authors are thankful to the management of Bangladesh Jute Research Institute (BJRI) and Delta Spinning Mills Ltd for providing the laboratory facilities for this study.

\section{References}

[1] Mahabubuzzaman, A.K.M., Miazi, M.O.G., Hossain, M.D. and Nabi, A.K. (2007) A Study on the Quality of Blended Jute Yarn through Two Different Process Line. Journal of Textile and Apparel, Technology and Management, 5, 1-5.

[2] Gordon, C.J. (2005) Handbook of Textile Fibres I. Natural Fibres. 5th Edition, Abington Hall, Abington, Cambridge, 13-16, 64-70.

[3] Ghosh, P. (2004) Effect of Selective Chemical Treatments of Jute Fiber on Textile-Related Properties and Processible. Indian Journal of Fibers \& Textile Research, 29, 85-89.

[4] Baheti, V., Militky, J. and Ul Hassan, S.Z. (2013) Polylactic Acid (PLA) Composite Films Reinforced with Wet Milled Jute Nanofibers. Conference Papers in Materials Science, 2013, Article ID: 738741. http://dx.doi.org/10.1155/2013/738741

[5] Bindal, A., Singh, S., Batra, N.K. and Khanna, R. (2013) Development of Glass/Jute Fibers Reinforced Polyester Composite. Indian Journal of Materials Science, 2013, Article ID: 675264. http://dx.doi.org/10.1155/2013/675264

[6] Khan, M., Roy, J., Akter, N., Zaman, H., Islam, T. and Khan, R. (2012) Production and Properties of Short Jute and Short E-Glass Fiber Reinforced Polypropylene-Based Composites. Open Journal of Composite Materials, 2, 40-47.

[7] Strumiłło, J.L., Cyniak, D., Czekalski, J. and Jackowski, T. (2007) Quality of Cotton Yarns Spun Using Ring-, Compact-, and Rotor-Spinning Machines as a Function of Selected Spinning Process Parameters. Fibres \& Textiles in Eastern Europe, 15, 60.

[8] Nawaz, S.M., Farooq, A. and Baig, S.A. (2008) Studies on Cottonized Jute Composite Structures Spun on Ring, Rotor 
and Air Jet Spinning Systems. International Conference on Flax and Other Bast Plants, 290-298.

[9] Sett, S.K., Mukherjee, A. and Siur, D. (2000) Tensile Characteristics of Rotor and Friction Spun Jute Blended Yarns. Textile Research Journal, 70, 723-728. http://dx.doi.org/10.1177/004051750007000810

[10] Abdus, S.M., Ahmed, F. and Mahabubuzzaman, A.K.M. (2012) Study on the Physical Properties of Jute-Cotton Blended Yarn. SUST Journal of Science and Technology, 20, 84-88.

[11] Atkinson, R.R. (1965) Jute Fibre to Yarn. Chemical Publishing Co., New York, 120-125.

[12] Ahmed, H.U. (1966) Speed and Production Calculation of Jute Spinning Machinery. Shahjahan Printing Works, Dhaka, $35 \& 67-71$.

[13] Mahabubuzzaman, A.K.M., Kabir, M.K. and Latifa, B.L. (2002) Study of the Effect of Speed Variation at Breaker Card Cylinder on Fibre Length and Yarn Quality. Asian journal of Plant Sciences, 6, 648-649.

[14] Ranjan, T.C. (1985) Handbook on Jute. 2nd Edition, Oxford \& IBH, New Delhi Bombay Calcutta, 186-193.

[15] Uster (2005) Uster ${ }^{\circledR}$ Tensojet 4 Application Report-Application of Single Fiber Testing System for Process Control in Spinning Mill. Uster Technologies AG, Swizerland, 5-10.

[16] Das, B.R. (2010) Tensile Behaviour of Spun Yarns under Static State. Journal of Engineered Fibers and Fabrics, 5, 19.

[17] Morton, W.E. and Hearle, J.W.S. (1975) Physical Properties of Textile Fibres. 2nd Edition, Textile Institute \& Heinemann, London, 265-275.

[18] Mahabubuzzaman, A.K.M., Latifa, B.L. and Asaduzzaman, M.A. (2003) Study on the Quality of Gardella Fine Yarn in Comparison to Modified Ring Spinning Frame. Pakistani Journal of Biological Sciences, 6, 76-77. http://dx.doi.org/10.3923/pjbs.2003.76.77

[19] Stout, P.H. (1988) Fibre and Yarn Quality in Jute Spinning. Manchester M3 5DR. The Textile Institute, United Kingdom, 1-10.

[20] Uster (2005) Application Report-Principles of Measurement of Opto-Electronic Sensor OM. Uster Technologies AG, Switzerland, 3-10.

[21] Uster (2013) Uster® Statistics Application Hand Book. Zellweger Uster, Switzerland, 19-22.

[22] Sheikh, H.R. (1994) Improvement of Yarn Quality by Reducing Yarn Imperfections. PakistanTextile Journal, 43, 36-37.

[23] El-mogahzy, Y., Etzold, S., Graser, S., Hoke, H., Peters, G. and Scott, G. (2005) Uster ${ }^{\circledR}$ Tester 5: A Multi-Purpose Laboratory System for the Analysis of Spun Yarns. Uster ${ }^{\circledR}$ News Bulletin No. 44, CH-8610 Uster/ Uster Technologies AG, Switzerland, 25-26. 